\title{
Study on corrosion inhibition efficiency of some quinazoline derivatives on stainless steel 304 in hydrochloric acid solutions ${ }^{\dagger}$
}

\author{
A.S. Fouda, ${ }^{1}$ M.A. El-Morsy, ${ }^{2}$ A. A. El-Barbary ${ }^{2}$ and Lamia E. Lamloum ${ }^{1}$ \\ ${ }^{1}$ Department of chemistry, Faculty of Science, Mansoura University, \\ Mansoura-35516, Egypt \\ ${ }^{2}$ Department chemistry, Faculty of Science, Tanta University, Tanta, Egypt \\ *E-mail: asfouda@hotmail.com
}

\begin{abstract}
The effect of the addition of some quinazoline derivatives on the corrosion of stainless steel 304 (SS 304) in hydrochloric acid medium was investigated using electrochemical frequency modulation (EFM), electrochemical impedance spectroscopy (EIS), potentiodynamic polarization, and weight reduction measurements, The inhibition efficiency increases with increasing the inhibitor concentration, but decreases with increasing the temperature. The adsorption of these compounds on the stainless steel 304 surface follows Langmuir isotherm. Potentiodynamic polarization studies showed that these compounds are mixed-type inhibitors. The results obtained from all the measurements are in good agreement. The effect of temperature in the range 298-328 K on the corrosion of stainless steel 304 in $1 \mathrm{M} \mathrm{HCl}$ was tested and thermodynamic parameters were computed and discussed.
\end{abstract}

Keywords: acid corrosion; stainless steel 304; quinazoline derivatives, weight loss.

Received: January 17, 2016. Published: March 28, 2016.

doi: $10.17675 / 2305-6894-2016-5-2-2$

\section{Introduction}

Stainless steel type 304 (SS 304) is large utilized in many applications such as construction materials, desalination plants, thermal power plant, pharmaceutical industry, pickling process, and chemical cleaning due to their good resistance corrosion, stability, high strength, weldability and workability. Corrosion is the deterioration of vital properties of material because reactions with its surroundings. Many of dollars are lost each year due to corrosion. This loss is due to the corrosion of steel and iron although many other materials may corrode as well. Corrosion destroy can cause losses of fluids or gases. Even more dangerous is a loss of strength of the structure induced by corrosion and subsequent failure. The application of acid corrosion inhibitors in the industry is largely used to prevent or decrease material loss during reaction with acid. It has been spotted that the adsorption

\footnotetext{
$\dagger$ Note from the Editors: The opinion of the authors that it is valid to calculate the degree of surface coverage by an inhibitor from corrosion data for compounds affecting the activation energy of corrosion does not fully agree with the views of the Editorial Board explained in detail in Int. J. Corros. Scale Inhib., 2015, 4, no. 2, 108.
} 
depends mainly on certain physicochemical properties of the inhibitor molecule such as steric factors, functional groups, electron density at the donor atoms $\pi$ orbital character of donating electrons also on the electronic structure of the inhibitor and aromaticity. It has been reported that many organic, inorganic, heterocyclic compounds containing heteroatoms like $\mathrm{P}, \mathrm{N}, \mathrm{S}$ and $\mathrm{O}$ have been proved effective inhibitors for the corrosion in acid media with stainless steel [1-30].

The aim of this paper is to describe an investigation of the corrosion protection of commercial SS 304 in $1 \mathrm{M} \mathrm{HCl}$ solutions by some quinazoline derivatives using chemical and electrochemical methods.

\section{Experimental}

The experiments were performed with the SS type 304, weight \%: $0.044 \mathrm{C}, 0.351 \mathrm{Si}$, $1.640 \mathrm{Mn}, 0.170 \mathrm{Co}, 0.026 \mathrm{P}, 0.014 \mathrm{~S}, 18.00 \mathrm{Cr}, 8.80 \mathrm{Ni}, 0.19 \mathrm{Mo}, 0.16 \mathrm{Cu}$ and $0.045 \mathrm{~N}$. The inhibitors used were selected from quinazoline derivatives with chemical structures shown in Table 1.

Table 1. Chemical structures of inhibitors.

Inhibitor

The quinazoline derivatives were prepared, purified and identified according to the recommended method [31] as follows:

Preparation of 3-phenyl-2-thioxo-2, 3-dihydro-1H-quinazolin-4-one [32].

2-Aminobenzoic acid ( $40 \mathrm{~g}, 0.2 \mathrm{~mol})$ was added to phenyl isothiocyanate $(0.2 \mathrm{~mol})$ in anhydrous pyridine $(25 \mathrm{ml})$. The mixture was refluxed for $5 \mathrm{~h}$ (TLC). The solvent was evaporated until dryness under vacuum, and the obtained solid was crystallized from methanol and dried to give $\mathbf{C 1}$, yield $53 \%$, m.p. $171-173^{\circ} \mathrm{C}$. 
Preparation of 3-amino-6-bromo-2-thioxo-2, 3-dihydro-1H-quinazolin-4-one [51].

A mixture of 2-amino-3,5-dibromobenzoic acid ethyl ester (10 g, $0.03 \mathrm{~mol})$, sodium hydroxide $(1.2 \mathrm{~g} ., 0.03 \mathrm{~mol})$ and carbon disulphide $\left(\mathrm{CS}_{2}\right)(0.75 \mathrm{ml} ., 0.035 \mathrm{~mol})$ were mixed with ethanol $(120 \mathrm{ml})$ and refluxed for $15 \mathrm{~h}$ (TLC). The solvent was evaporated under reduced pressure. The obtained solid was dissolved in water $(100 \mathrm{ml})$ and neutralized with $\mathrm{HCl}(1: 1)$. The formed precipitate was filtered off, rinsed with water and recrystallized from ethanol to give $\mathbf{C 2}$, yield $50 \%$, m.p. $260^{\circ} \mathrm{C}$.

\section{Solutions}

The corrosive solutions, $1 \mathrm{M} \mathrm{HCl}$ were prepared by dilution of Analar $\mathrm{HCl}(67.5 \% \mathrm{BDH}$ grade) with bidistilled water. All reagents and chemicals were of pure grade. The measurements were performed in $1 \mathrm{M} \mathrm{HCl}$ without and with the presence of the used compounds in the concentration range $\left(1 \times 10^{-6}\right.$ to $\left.21 \times 10^{-6} \mathrm{M}\right)$. Table 1 shows the names, structures, molecular formulas and molecular weights of these additives.

\section{Mass loss tests}

Seven parallel SS 304 sheets of $2 \times 2 \times 0.2 \mathrm{~cm}$ were abraded with different grades of emery paper up to 1200 grit size and then rinsed with bi-distilled water and acetone and weighed. The specimens were immersed in a $150 \mathrm{ml}$ beaker, which contained $100 \mathrm{ml}$ of $\mathrm{HCl}$ with and without addition of different concentrations of the investigated derivatives. All the solutions were open to air. After $3 \mathrm{~h}$, the specimens were removed, rinsed, dried, and weighed again. The average weight loss of the seven parallel SS 304 sheets could be obtained. The degree of surface coverage, $\theta$, and the protection efficiency (IE \%) of investigated compounds were calculated from Eq. (1) [33]:

$$
I E \%=\theta \times 100=\left[1-\left(W / W^{0}\right)\right] \times 100,
$$

where $W^{0}$ and $W$ are the values of the average mass loss without and with addition of the additives, respectively

\section{Electrochemical tests}

\section{Potentiodynamic polarization test}

Polarization experiments were carried out in a conventional three-electrode cell with a saturated calomel electrode (SCE) coupled to a fine Luggin capillary as reference electrode and platinum gauze as auxiliary electrode. The working electrode was in the form of a square cut from SS 304 sheet of the same composition embedded in epoxy resin so that the surface area was $1 \mathrm{~cm}^{2}$. Prior to each measurement, the electrode surface was pretreated in the same manner as the mass loss tests. Before measurements, the electrode was dipped in solution for 20 min until a steady state was reached. The potential was started from +400 to $-600 \mathrm{mV} v s$. open circuit potential $\left(E_{\text {ocp }}\right)$. All experiments were performed in freshly prepared solutions at $25^{\circ} \mathrm{C}$ and results were always repeated at least two times to check the 
reproducibility. The surface coverage $(\theta)$ and the inhibition efficiency were obtained as follows:

$$
I E \%=\theta \times 100=\left(1-\left(i_{\text {corr }} / i_{\text {corr }}^{0}\right)\right) \times 100,
$$

where $i_{\text {corr }}$ and $i_{\text {corr }}^{0}$ are corrosion current densities with and without the presence of additives, respectively.

\section{EIS tests}

EIS tests were performed using AC signals of $5 \mathrm{mV}$ peak to peak amplitude at the open circuit potential in the frequency range of $0.1 \mathrm{~Hz}$ to $100 \mathrm{kHz}$. Appropriate equivalent circuit was used to fit EIS data using the Gamry Echem Analyst software version 6.03.

\section{EFM tests}

EFM tests were performed with applying potential perturbation signal with amplitude 10 $\mathrm{mV}$ with two sine waves $(2$ and $5 \mathrm{~Hz}$ ). The choice for the frequencies of 2 and $5 \mathrm{~Hz}$ was based on three arguments [34-35]. The larger peaks were used to calculate the Tafel slopes ( $\beta_{\mathrm{c}}$ and $\beta_{\mathrm{a}}$ ), the causality factors CF-2 and CF-3 [36] and corrosion current density ( $\left.i_{\text {corr }}\right)$.

Gamry Instrument Potentiostat/Galvanostat/ZRA (PCI4-G750) was used for all electrochemical tests. This includes a Gamry framework system v 6.03. Gamry applications include EIS300 software for electrochemical EIS tests, DC105 software for DC corrosion tests, and EFM140 for EFM tests along with a computer for collecting data. Echem analyst v 6.03 software was used for plotting, graphing, and fitting data.

\section{Quantum calculation}

All the quantum chemical study has been performed using semi-empirical method (PM3), available by Material studio version 6 . Molecular orbital calculation was based on semiempirical method. This method has been used with full geometry optimization.

\section{Results and Discussion}

\section{Chemical method (Mass-loss measurements)}

Mass-loss of SS 304 was determined, at different time intervals, with and without different concentrations of quinazoline additives $(\mathbf{C} 1 \& \mathbf{C 2})$. The obtained mass-loss time curves are shown in Figure 1 for compound (C2), the most efficient one. Similar curves were obtained for compound (C1) (not shown). The protection efficiency was found to be dependent on the inhibitor concentration. The curves obtained in the presence of inhibitors fall significantly below that of free acid. In all cases, the increase in the concentration of additives was accompanied by a decrease in mass-loss and an increase in the \% protection. These results lead to the conclusion that these compounds are efficient inhibitors for SS 304 dissolution in $\mathrm{HCl}$ solution. Also, the degree of surface coverage $(\Theta)$ would increase by increasing the inhibitor concentration. In order to get a comparative view, the 
variation of the percentage protection (IE \%) of the two inhibitors with their molar concentrations was calculated. The values obtained are summarized in Table 2. Careful inspection of these results showed that, at the same inhibitor concentration, the order of inhibition efficiency is as follows: $\mathbf{C 2}>\mathbf{C 1}$.

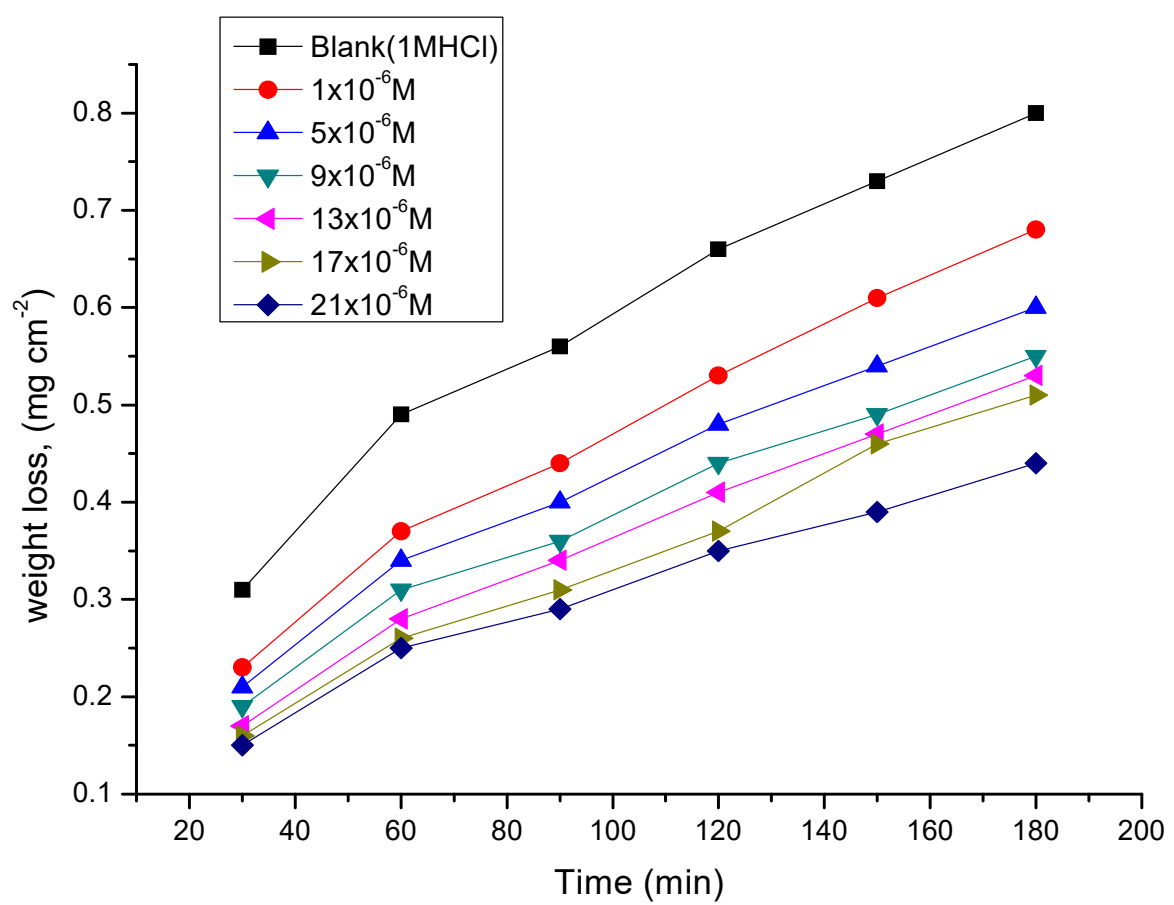

Figure 1. Mass loss-time curves for SS 304 corrosion in $1 \mathrm{M} \mathrm{HCl}$ with and without different concentrations of $\mathbf{C 1}$ at $25^{\circ} \mathrm{C}$.

Table 2. Protection efficiencies (IE \%) and surface coverage $(\theta)$ values of $\mathbf{C 1}$ and $\mathbf{C 2}$ for the corrosion of SS 304 in $1 \mathrm{M} \mathrm{HCl}$ from mass-loss tests at different concentrations and at $25^{\circ} \mathrm{C}$.

\begin{tabular}{ccccc}
\hline \multirow{2}{*}[\mathbf{inh}]{$\times \mathbf{1 0}^{\mathbf{6}} \mathbf{M}$} & $\boldsymbol{C} 1$ & $\boldsymbol{2}$ & $\mathbf{C 2}$ \\
\cline { 2 - 5 } & 0.197 & 19.7 & 0.212 & $\boldsymbol{I E} \%$ \\
\hline 1 & 0.273 & 27.3 & 0.318 & 21.2 \\
5 & 0.333 & 33.3 & 0.409 & 31.8 \\
9 & 0.379 & 37.9 & 0.439 & 40.9 \\
13 & 0.439 & 43.9 & 0.470 & 43.9 \\
17 & 0.470 & 47.0 & 0.515 & 47.0 \\
21 & & & & 51.5 \\
\hline
\end{tabular}




\section{Effect of temperature on corrosion rate}

The effect of temperature on the corrosion rate of SS 304 in $1 \mathrm{M} \mathrm{HCl}$ and with different inhibitor concentrations was studied in the temperature range of $25-45^{\circ} \mathrm{C}$ using weight loss measurements. Similar curves were obtained for other inhibitors (not shown). As the temperature increases, the rate of corrosion increase and the protection efficiency of the $\mathbf{C 1}$ and $\mathbf{C 2}$ decreases as shown in Table 3 for inhibitor (C2), the most efficient one. Similar Tables were obtained for C1 (not shown). The adsorption behavior of inhibitors on SS 304 surface occurs through physical adsorption.

Table 3. Protection efficiencies $I E \%$ and corrosion rate $(\mathrm{CR})$ values of inhibitor $(\mathbf{C} 2)$ for the dissolution of SS 304 in $1 \mathrm{M} \mathrm{HCl}$ from mass-loss tests at different concentrations at temperature range of $25-45^{\circ} \mathrm{C}$.

\begin{tabular}{|c|c|c|c|c|c|c|c|c|c|c|}
\hline \multirow{2}{*}[\operatorname{inh}]{$\times 10^{6} M$} & \multicolumn{2}{|c|}{$298 K$} & \multicolumn{2}{|c|}{$303 \mathrm{~K}$} & \multicolumn{2}{|c|}{$308 \mathrm{~K}$} & \multicolumn{2}{|c|}{$313 \mathrm{~K}$} & \multicolumn{2}{|c|}{$318 K$} \\
\hline & CR & $I E \%$ & CR & $I E \%$ & CR & $I E \%$ & CR & $I E \%$ & CR & $I E \%$ \\
\hline 1 & 0.0044 & 19.7 & 0.0037 & 18.5 & 0.0065 & 16.1 & 0.0077 & 14.8 & 0.0097 & 13.4 \\
\hline 5 & 0.0040 & 27.3 & 0.0033 & 25.9 & 0.0060 & 22.6 & 0.0072 & 20.4 & 0.0091 & 18.7 \\
\hline 9 & 0.0037 & 33.3 & 0.0031 & 31.5 & 0.0053 & 31.2 & 0.0063 & 29.6 & 0.0081 & 27.6 \\
\hline 13 & 0.0034 & 37.9 & 0.0029 & 35.2 & 0.0052 & 33.3 & 0.0063 & 30.6 & 0.0079 & 29.1 \\
\hline 17 & 0.0031 & 43.9 & 0.0028 & 38.9 & 0.0049 & 36.6 & 0.0059 & 34.3 & 0.0078 & 30.6 \\
\hline 21 & 0.0029 & 47.0 & 0.0024 & 46.3 & 0.0045 & 41.9 & 0.0055 & 38.9 & 0.0073 & $35 . .1$ \\
\hline
\end{tabular}

\section{Adsorption isotherms}

The adsorption isotherm that characterizes the metal/inhibitor/environment system is the most suitable way to express adsorption quantitatively. $\theta$ values were applied to various adsorption isotherms, the results were fitted well with Langmuir adsorption isotherm, which are represented in Figure 2 for $\mathbf{C} \mathbf{1}$ and $\mathbf{C 2}$, Langmuir adsorption isotherm expressed by:

$$
\theta /(1-\theta)=K_{\mathrm{ads}} C,
$$

where $K_{\text {ads }}$ is the adsorption equilibrium constant and $C$ is the concentration $\left(\mathrm{mol} \mathrm{L}^{-1}\right)$ of the inhibitor in the bulk electrolyte. A plot of $\theta /(1-\theta)$ versus $C$ should give straight lines with slope equal to $K_{\text {ads. }}$. In order to get a comparative view, the variation of the adsorption equilibrium constant of $\mathbf{C 1}$ and $\mathbf{C 2}$ with their molar concentrations was calculated. The experimental data give straight lines with good curves fitting for the applied adsorption isotherm as the correlation coefficients $\left(R^{2}\right)$ were in the range $(0.853-0.967)$. The values obtained are given in Table 4. These results confirm the assumption that these compounds (C1 and C2) are adsorbed on the SS 304 surface via the protonated atoms or via the lone pair of electrons of present donating atoms. The extent of protection is directly related to the performance of adsorption layer which is a sensitive function of the molecular 
structure. The equilibrium constant obtained from slopes of Langmuir adsorption isotherm is related to the free energy of adsorption $\Delta G_{\text {ads }}^{0}$ as follows:

$$
K_{\text {ads }}=1 / 55.5 \exp \left(\frac{-\Delta G_{\text {ads }}^{0}}{R T}\right),
$$

where 55.5 is the molar concentration of water in the solution in $\mathrm{M}^{-1}$.

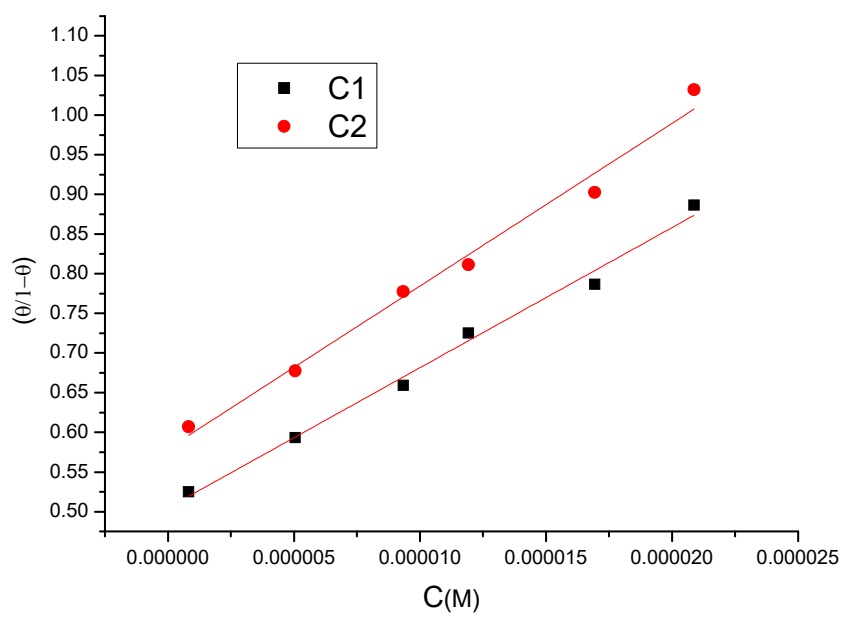

Figure 2. Langmuir adsorption isotherm of inhibitors (C1) and (C2) on SS 304 surface in $1 \mathrm{M}$ $\mathrm{HCl}$ at $25^{\circ} \mathrm{C}$.

Plot of $\left(\Delta G_{\text {ads }}^{0}\right)$ versus $1000 / T$ (Figure 3) gave a straight line, the slope of these lines give the heat of adsorption $\left(\Delta H_{\text {ads }}^{0}\right)$ and the standard entropy $\left(\Delta S_{\text {ads }}^{0}\right)$ according to Gibbs equation at constant temperature (Eq. 5):

$$
\Delta G_{\mathrm{ads}}^{0}=\Delta H_{\mathrm{ads}}^{0}-T \Delta S_{\mathrm{ads}}^{0}
$$

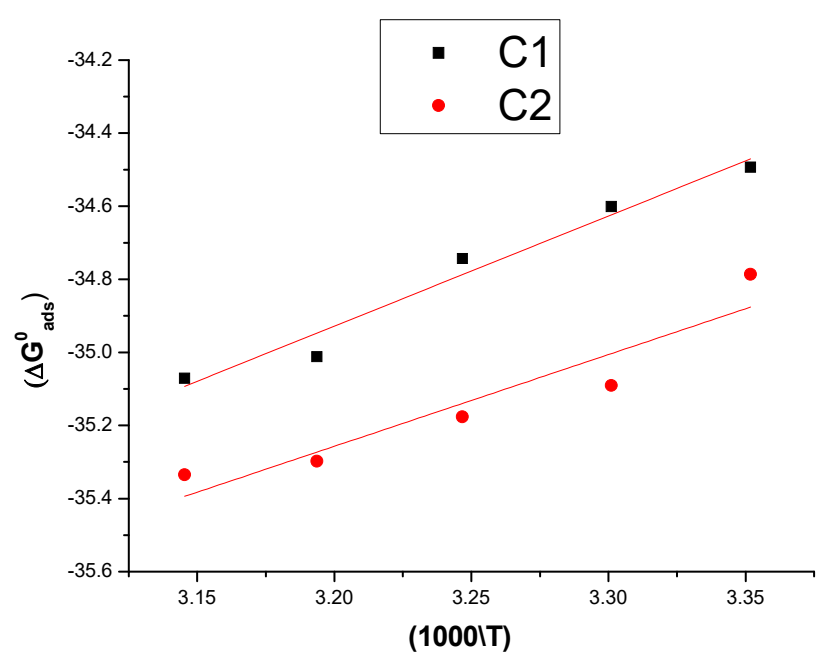

Figure 3. Variation of $\left(\Delta G_{\text {ads }}^{0}\right)$ versus $(1000 / T)$ for the adsorption of $\mathbf{C} 1$ and $\mathbf{C 2}$ on SS 304 surface in $1 \mathrm{M} \mathrm{HCl}$ at various temperatures. 
Table 5 clearly shows a good dependence of $\Delta G_{\text {ads }}^{0}$ on $T$, indicating the good correlation among thermodynamic parameters. The negative values of $\Delta G_{\text {ads }}^{0}$ indicate the spontaneity of the adsorption process and stability of the adsorbed layer of $\mathbf{C} \mathbf{1}$ and $\mathbf{C 2}$ on the SS 304 surface. When the values of $\Delta G_{\text {ads }}^{0}$ are around $-20 \mathrm{~kJ} \mathrm{~mol}^{-1}$ or lower, this is consistent with physical adsorption, and when these values are around $-40 \mathrm{~kJ} \mathrm{~mol}^{-1}$ or higher, this is consistent with chemisorption [57]. The calculated $\Delta G_{\text {ads }}^{0}$ values are closer to $-35 \mathrm{~kJ} \mathrm{~mol}^{-1}$ indicating that the adsorption mechanism of $\mathbf{C 1}$ and $\mathbf{C 2}$ on SS 304 in $1 \mathrm{M}$ $\mathrm{HCl}$ solutions is typical of mixed type adsorption (i.e., physisorption and chemisorption). The unshared electron pairs in sulphur, nitrogen as well as in oxygen may interact with dorbitals of SS 304 to provide a protective physical adsorbed film [37]. The higher values of $K_{\text {ads }}$ indicate the higher stability of adsorbed layer on SS 304 and the values of $K_{\text {ads }}$ run parallel to $I E \%$. The values of thermodynamic parameter for the adsorption of inhibitors (Table 5) can provide valuable information about the mechanism of corrosion protection. While an endothermic adsorption process $\left(\Delta H_{\text {ads }}^{0}>0\right)$ is attributed unequivocally to chemisorption [38], an exothermic adsorption process $\left(\Delta H_{\text {ads }}^{0}<0\right)$ may involve either physisorption or chemisorption or mixture of both processes. In the presented case, the calculated values of $\Delta H_{\text {ads }}^{0}$ for the adsorption of inhibitors in $1 \mathrm{M} \mathrm{HCl}$ are negative indicating that these inhibitors may be physically or chemically adsorbed on SS 304 surface. The $\Delta S_{\text {ads }}^{0}$ values in the presence of inhibitors in $1 \mathrm{M} \mathrm{HCl}$ are negative. This indicates that an increase in disorder takes places on going from reactants to the activated state [39].

Table 5. Calculated thermodynamic functions for the adsorption of $\mathbf{C 1}$ and $\mathbf{C 2}$ on SS 304 surface in $1 \mathrm{M}$ $\mathrm{HCl}$ at various temperatures.

\begin{tabular}{|c|c|c|c|c|c|}
\hline Inhibitor & $\begin{array}{c}\text { Temperature, } \\
{ }^{\circ} \mathbf{C}\end{array}$ & $K_{\mathrm{ads},}, \mathbf{M}^{-1}$ & $\begin{array}{c}\Delta G_{\text {ads }}^{0}, \\
\mathbf{k J} \mathbf{~ m o l}^{-1}\end{array}$ & $\begin{array}{c}\Delta H_{\mathrm{ads}}^{0}, \\
\mathbf{k J} \mathbf{~ m o l}^{-\mathbf{1}}\end{array}$ & $\begin{array}{c}\Delta S_{\text {add }}^{0}, \\
\mathbf{J} \mathbf{~ m o l}^{-1} \mathbf{K}^{-1}\end{array}$ \\
\hline \multirow{5}{*}{ C1 } & 25 & 18448.0 & 34.3 & \multirow{5}{*}{22.7} & 115.00 \\
\hline & 30 & 16777.3 & 34.6 & & 114.21 \\
\hline & 35 & 14030.3 & 34.7 & & 112.74 \\
\hline & 40 & 13301.6 & 35.2 & & 112.29 \\
\hline & 45 & 10060.7 & 35.0 & & 109.97 \\
\hline \multirow{5}{*}{$\mathrm{C} 2$} & 25 & 24835.7 & 34.9 & \multirow{5}{*}{17.1} & 117.15 \\
\hline & 30 & 23127.7 & 35.6 & & 117.25 \\
\hline & 35 & 16615.5 & 35.2 & & 114.15 \\
\hline & 40 & 13981.1 & 35.3 & & 112.72 \\
\hline & 45 & 11212.5 & 35.3 & & 110.88 \\
\hline
\end{tabular}




\section{Kinetic-thermodynamic corrosion parameters}

The activation energy for the dissolution process was computed from Arrhenius-type plot according to Eq. (6):

$$
k_{\mathrm{corr}}=A \exp \left(E_{a}^{*} / R T\right)
$$

where $E_{a}^{*}$ is the activation corrosion energy, $R$ is the gas constant, $T$ is the absolute temperature, $A$ is the Arrhenius pre-exponential constant and $k_{\text {corr }}$ is the rate of corrosion. Values of apparent activation energy of corrosion of SS 304 in $1 \mathrm{M} \mathrm{HCl}$ without and with various concentrations of compound (C2) are shown in Table 6 . The values of $E_{a}^{*}$ were determined from the slope of $\log \left(k_{\text {corr }}\right)$ versus $1000 / T$ (Figure 4$)$. The data show that $E_{a}^{*}$ is higher in the presence of $\mathbf{C 1}$ and $\mathbf{C 2}$ than in its absence. This was attributed to the formation of an energy barrier on SS 304 surface. The alternative formulation of transition state equation is shown in Eq. (7):

$$
k_{\text {corr }}=(R T / N h) \exp \left(\Delta S^{*} / R\right) \exp \left(-\Delta H^{*} / R T\right),
$$

where $k_{\text {corr }}$ is the rate of metal dissolution, $h$ is Planck's constant, $N$ is Avogadro's number, $\Delta S^{*}$ is the entropy of activation and $\Delta H^{*}$ is the enthalpy of activation. Figure 4 shows a plot of $\log k$ against $(1000 / T)$ in the case of inhibitor (C2) in $1 \mathrm{M} \mathrm{HCl}$. Similar behavior is observed in the case of inhibitor C1. Straight lines are obtained with a slopes equal to $\left(\Delta H^{*} / 2.303 R\right)$ and intercepts are $\left[\log \left(R / N h+\Delta S^{*} / 2.303 R\right)\right]$ (Table 6). The increase in $E_{a}^{*}$ with an increase in inhibitor concentration is typical of physical adsorption. The positive signs of the enthalpies $\left(\Delta H^{*}\right)$ reflect the endothermic nature of the SS 304 corrosion process. The negative values of entropies $\left(\Delta S^{*}\right)$ imply that at the rate determining step, activated complex represents an association rather than dissociation step. This means that there is a decrease in disordering on going from reactants to the activated complex $[39,40]$. However, the value of $\left(\Delta S^{*}\right)$ decreases gradually with increasing inhibitor concentration in all the acid media. 


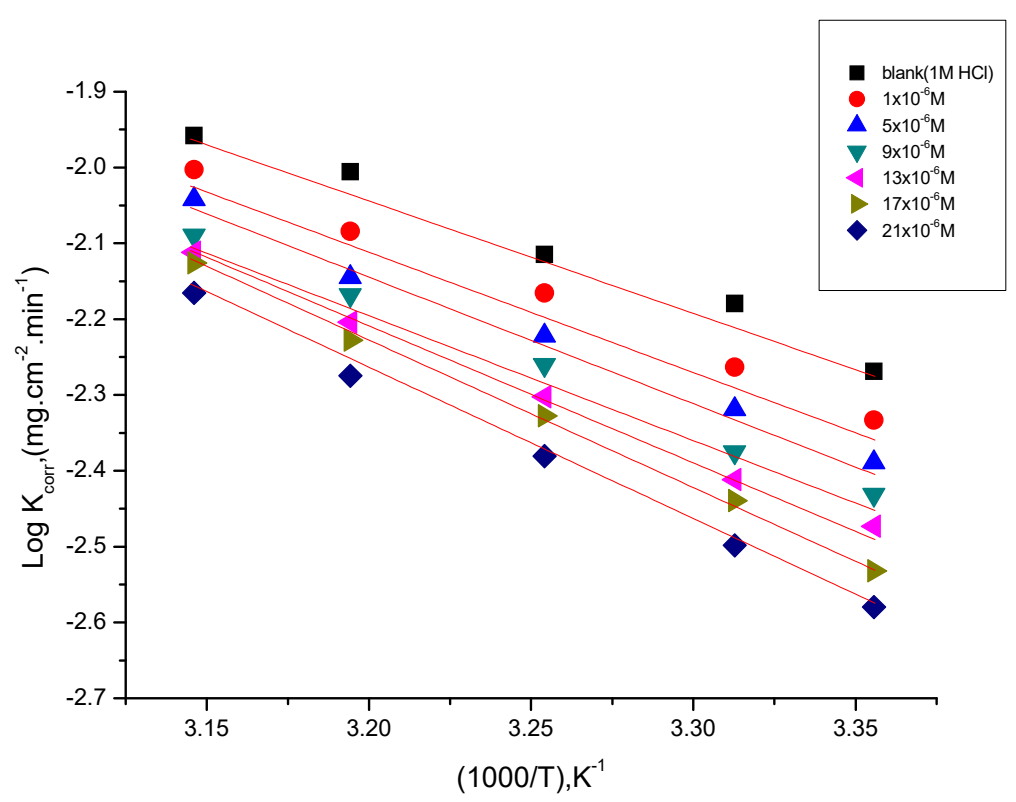

Figure 4. $\log k_{\text {corr }} v s .(1000 / T)$ curves for Arrhenius plots for SS 304 corrosion rates $\left(k_{\text {corr }}\right)$ after $2 \mathrm{~h}$ of immersion in $1 \mathrm{M} \mathrm{HCl}$ with and without various concentrations of inhibitor (C2).

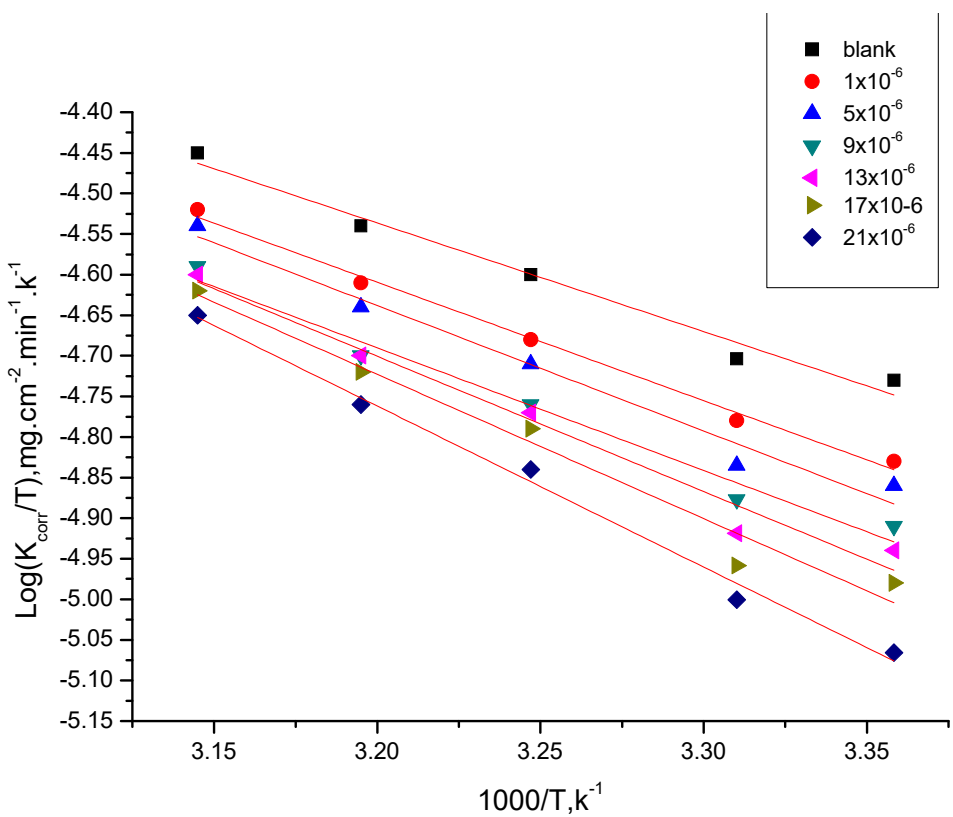

Figure 5. $\log \left(k_{\text {corr }} / T\right)$ vs. $(1000 / T)$ curves for transition plots for SS 304 corrosion rates $\left(k_{\text {corr }}\right)$ after $2 \mathrm{~h}$ of immersion in $1 \mathrm{M} \mathrm{HCl}$ with and without various concentrations of $\mathbf{C 2}$. 
Table 6. Calculated activation functions for SS 304 corrosion with and without various concentrations of $\mathbf{C 1}$ and $\mathbf{C 2}$ in $1 \mathrm{M} \mathrm{HCl}$ solutions.

\begin{tabular}{|c|c|c|c|c|}
\hline Compound & Conc. $\times 10^{6}, M$ & $E_{a}^{*}, \mathbf{k J} \mathbf{~ m o l}^{-1}$ & $\Delta H^{*}, \mathrm{~kJ} \mathrm{~mol}^{-1}$ & $\begin{array}{c}\Delta S^{*}, \\
\mathbf{J ~ m o l}^{-1} \mathbf{K}^{-1}\end{array}$ \\
\hline Blank & 0.0 & 28.4 & 11.1 & 202.36 \\
\hline \multirow{6}{*}{$\mathrm{C1}$} & 1 & 30.4 & 12.1 & 196.43 \\
\hline & 5 & 32.0 & 12.9 & 191.64 \\
\hline & 9 & 32.5 & 12.6 & 194.90 \\
\hline & 13 & 34.4 & 13.9 & 185.51 \\
\hline & 17 & 37.2 & 14.8 & 179.00 \\
\hline & 21 & 38.2 & 16.5 & 167.13 \\
\hline \multirow{6}{*}{$\mathrm{C2}$} & 1 & 29.9 & 12.8 & 191.78 \\
\hline & 5 & 30.3 & 13.1 & 190.74 \\
\hline & 9 & 32.6 & 13.3 & 190.21 \\
\hline & 13 & 33.0 & 15.4 & 174.94 \\
\hline & 17 & 33.4 & 16.3 & 169.75 \\
\hline & 21 & 39.9 & 16.0 & 172.86 \\
\hline
\end{tabular}

\section{Potentiodynamic polarization measurements}

Figure 6 shows polarization curves for SS 304 in $1.0 \mathrm{M} \mathrm{HCl}$ solution. The two distinct regions that appeared were the active dissolution region (apparent Tafel region), and the limiting current region. In the inhibitor-free solution, the anodic polarization curve of SS 304 showed a monotonic increase of current with potential until the current reached the maximum value. After this maximum current density value, the current density declined rapidly with potential increase, forming an anodic current peak that was related to film formation. In the presence of inhibitor, both the cathodic and anodic current densities were greatly decreased over a wide potential range. Various corrosion parameters such as corrosion potential $\left(E_{\text {corr }}\right)$, anodic and cathodic Tafel slopes $\left(\beta_{\mathrm{a}}, \beta_{\mathrm{c}}\right)$, the corrosion current density $\left(i_{\text {corr }}\right)$, the degree of surface coverage $(\theta)$ and the inhibition efficiency $(I E \%)$ are given in Table 7. It can be seen from the experimental results that in all cases, addition of inhibitors induced a significant decrease in cathode and anodic currents. The values of $E_{\text {corr }}$ were affected and slightly changed by the addition of inhibitors. This indicates that these inhibitors act as mixed-type inhibitors. The slopes of anodic and cathodic Tafel lines $\left(\beta_{\mathrm{a}}\right.$ and $\beta_{c}$ ) were slightly changed (Tafel lines are parallel) on increasing the concentration of the tested compounds which indicates that there is no change of the mechanism of inhibition in the presence and absence of inhibitors. The orders of inhibition efficiency of all inhibitors at different concentrations as given by polarization measurements are listed in 
Table 7. The results are in good agreement with those obtained from weight-loss measurements.

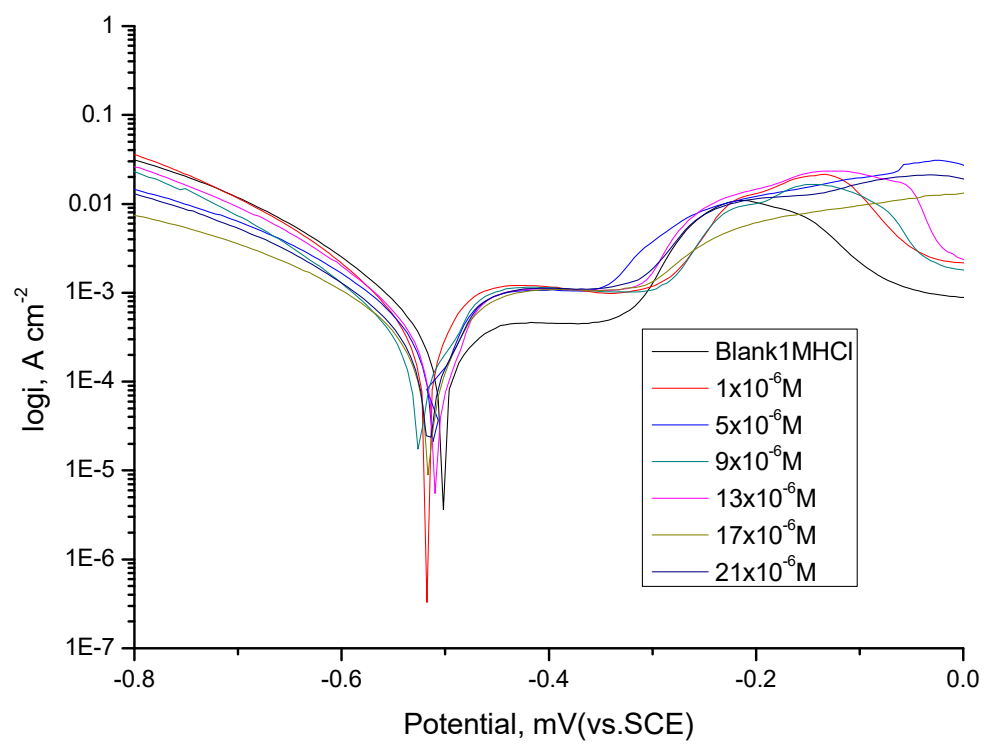

Figure 6. Polarization curves for the dissolution of SS 304 in $1.0 \mathrm{M} \mathrm{HCl}$ with and without different concentrations of $\mathbf{C 2}$ at $25^{\circ} \mathrm{C}$.

Table 7. Corrosion current density $\left(i_{\text {corr }}\right)$, corrosion potential $\left(E_{\text {corr }}\right)$, Tafel slopes $\left(\beta_{\mathrm{c}}, \beta_{\mathrm{a}}\right)$, inhibition efficiency $(I E \%)$ and degree of surface coverage $(\theta)$ of SS $3041 \mathrm{M} \mathrm{HCl}$ at $25^{\circ} \mathrm{C}$ for investigated compounds.

\begin{tabular}{|c|c|c|c|c|c|c|c|}
\hline Inhibitor & {$[\mathrm{inh}] \times 10^{6}, \mathrm{M}$} & $\begin{array}{c}-E_{\text {corr }} \\
\mathrm{mV} \text { vs. SCE }\end{array}$ & $\begin{array}{c}i_{\text {corr }} \\
\mu \mathrm{A} \mathrm{cm}^{-2}\end{array}$ & $\begin{array}{c}\boldsymbol{\beta}_{\mathrm{a}}, \\
\mathrm{mV} \operatorname{dec}^{-1}\end{array}$ & $\begin{array}{c}\beta_{c}, \\
m \operatorname{dec}^{-1}\end{array}$ & $\boldsymbol{\theta}$ & $I E \%$ \\
\hline Blank & 0 & 525 & 787 & 410 & 167 & - & - \\
\hline \multirow{6}{*}{ C1 } & 1 & 518 & 666 & 447 & 128 & 0.154 & 15.4 \\
\hline & 5 & 516 & 643 & 334 & 164 & 0.183 & 18.3 \\
\hline & 9 & 515 & 602 & 438 & 166 & 0.235 & 23.5 \\
\hline & 13 & 511 & 568 & 470 & 153 & 0.278 & 27.8 \\
\hline & 17 & 509 & 544 & 406 & 238 & 0.309 & 30.9 \\
\hline & 21 & 502 & 542 & 375 & 178 & 0.310 & 31.0 \\
\hline \multirow{6}{*}{$\mathrm{C} 2$} & 1 & 492 & 201 & 410 & 140 & 0.745 & 74.5 \\
\hline & 5 & 466 & 250 & 214 & 119 & 0.809 & 80.9 \\
\hline & 9 & 465 & 241 & 244 & 136 & 0.821 & 82.1 \\
\hline & 13 & 463 & 236 & 241 & 125 & 0.827 & 82.7 \\
\hline & 17 & 457 & 220 & 260 & 121 & 0.848 & 84.8 \\
\hline & 21 & 456 & 219 & 232 & 120 & 0.849 & 84.9 \\
\hline
\end{tabular}




\section{EIS measurements}

EIS is good technique for studying the corrosion. Electrode kinetics, surface properties, and mechanistic information can be obtained from EIS diagrams [41-44]. Figure 8 represents the Nyquist $(a)$ and Bode $(b)$ diagrams obtained at $E_{\text {ocp }}$ with and without increasing concentrations of studied compound $(\mathbf{C 2})$ at $25^{\circ} \mathrm{C}$. Similar curves were obtained for $\mathbf{C 1}$ (not shown). The increase in the size of the capacitive loop with the addition of investigated $\mathbf{C 1}$ and $\mathbf{C 2}$ shows that a barrier gradually forms on the SS 304 surface. The increase in the capacitive loop size (Figure 8a) enhances, at a certain inhibitor concentration, following the order: $\mathbf{C 2}>\mathbf{C 1}$. Bode plots (Figure 8b) show that the total impedance increases with increasing inhibitor concentration $(\log Z v s . \log f)$. But $(\log f v s$. phase), also Bode plot shows the continuous increase in the phase angle shift, obviously correlating with the increase of inhibitor adsorbed on SS 304 surface. The Nyquist plots yield semicircles and not perfect circles as expected from the theory of EIS. The deviation from ideal semicircle was generally attributed to the frequency dispersion [45] as well as to the inhomogeneity of the surface. EIS spectra of the investigated $\mathbf{C 1}$ and $\mathbf{C 2}$ were analyzed using the equivalent circuit, Figure 7, which represents a single charge transfer reaction and fits well with our experimental results. The constant phase element, CPE, is introduced in the circuit instead of a pure double layer capacitor to give a more accurate fit [46]. The double layer capacitance, $C_{\mathrm{dl}}$, for a circuit including a CPE parameter $\left(Y_{0}\right.$ and $\left.n\right)$ were calculated from Eq. (8) [47]:

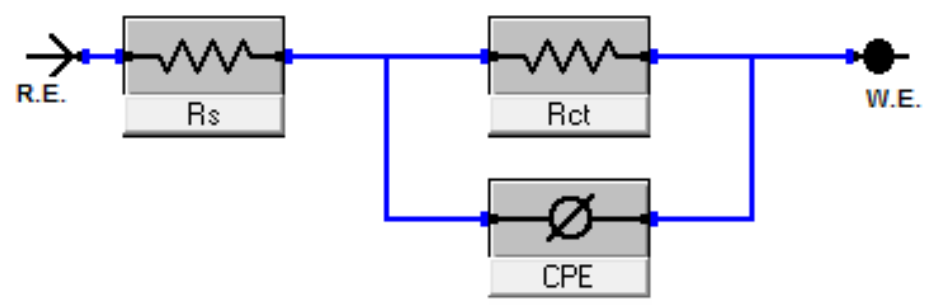

Figure 7. Circuit used to fit experimental EIS data.

$$
C_{\mathrm{dl}}=Y_{0}\left(\omega_{\max }\right)^{n-1}
$$

where $Y_{0}$ is the magnitude of the CPE, $\omega_{\max }=2 \pi f_{\max }, f_{\max }$ is the maximum frequency. After analyzing the shape of the Nyquist diagram, it is concluded that the corrosion process was mainly charge-transfer controlled $[52,53]$. The general shape of the curves is very similar for all samples indicating no change in the corrosion mechanism [50]. From EIS data in Table 8, the values of $\mathrm{R}_{\mathrm{ct}}$ increases with increasing the concentration of the $\mathrm{C} 1$ and $\mathrm{C} 2$ and hence \% IE $\mathrm{IEIS}_{\mathrm{EIS}}$, increases. In fact the presence of $\mathbf{C} \mathbf{1}$ and $\mathbf{C} \mathbf{2}$ enhances the value of $R_{\mathrm{ct}}$ in acidic solution. Values of double layer capacitance are also brought down to the maximum extent in the presence of $\mathbf{C} \mathbf{1}$ and $\mathbf{C 2}$ and the decrease in the values of CPE follows the order similar to that obtained for $i_{\text {corr }}$ in this study. The decrease in CPE/ $C_{\mathrm{dl}}$ results from a decrease in local dielectric constant and/or an increase in the thickness of the double layer, 
suggesting that organic derivatives inhibit the copper corrosion by adsorption at metal/acid [51-54]. The protection efficiency was calculated from Eq. (8) [55]:

$$
I E \%_{\text {EIS }}=\left[1-\left(R_{\mathrm{ct}}^{0} / R_{\mathrm{ct}}\right)\right] \times 100,
$$

where $R_{\mathrm{ct}}^{0}$ and $R_{\mathrm{ct}}$ are the charge-transfer resistance values without and with inhibitor, respectively.

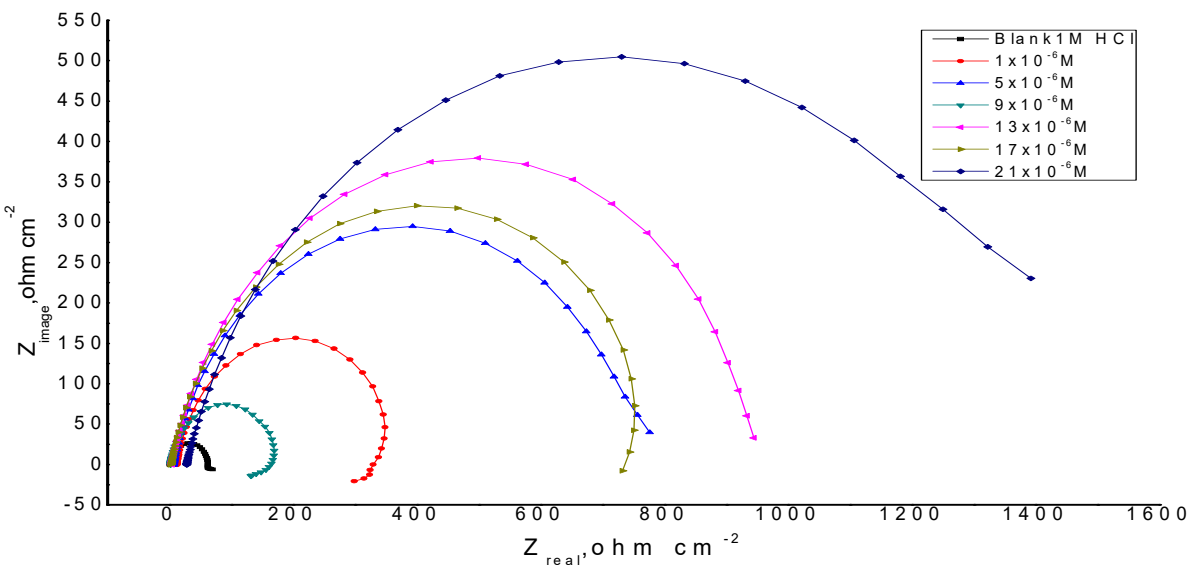

Figure 8a. The Nyquist diagram for the corrosion of SS 304 in $1.0 \mathrm{M} \mathrm{HCl}$ without and with of different concentrations of inhibitor $(\mathbf{C 2})$ at $25^{\circ} \mathrm{C}$.

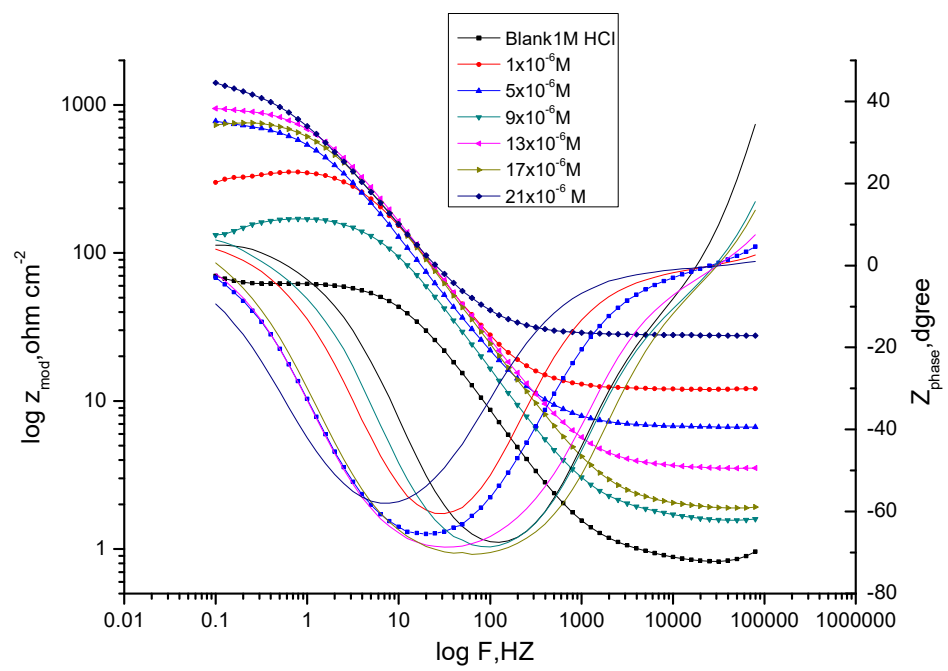

Figure 8b. The Bode diagram for the corrosion of SS 304 in $1.0 \mathrm{M} \mathrm{HCl}$ in the absence and presence of different concentrations of inhibitor $(\mathbf{C 2})$ at $25^{\circ} \mathrm{C}$. 
Table 8. Electrochemical parameters obtained by EIS technique for in $1.0 \mathrm{M} \mathrm{HCl}$ without and with various concentrations of $\mathbf{C 1}$ and $\mathbf{C 2}$ at $25^{\circ} \mathrm{C}$.

\begin{tabular}{cccccc}
\hline Inhibitor & {$[\mathbf{i n h}] \times \mathbf{1 0}^{-\mathbf{6}}, \mathbf{M}$} & $\mathbf{R}_{\mathbf{c t}}, \boldsymbol{\Omega} \mathbf{~ c m}^{\mathbf{2}}$ & $\mathbf{C}_{\mathbf{d l}}, \boldsymbol{\mu} \mathbf{F} \mathbf{~ c m}^{-\mathbf{2}}$ & $\boldsymbol{\theta}$ & $\boldsymbol{I E} \mathbf{\%}$ \\
\hline \multirow{2}{*}{ Blank } & 0 & 58.25 & 186 & - & - \\
\hline \multirow{2}{*}{$\mathbf{C 1}$} & 1 & 240.50 & 182 & 0.758 & 75.8 \\
& 5 & 244.20 & 176 & 0.761 & 76.1 \\
& 9 & 248.80 & 168 & 0.766 & 76.6 \\
& 13 & 267.2 & 146 & 0.782 & 78.2 \\
& 17 & 426.9 & 136 & 0.864 & 86.4 \\
& 21 & 563.30 & 103 & 0.897 & 89.7 \\
\hline \multirow{2}{*}{ C2 } & 1 & 149.4 & 129 & 0.610 & 61.0 \\
& 5 & 249.5 & 113 & 0.815 & 76.7 \\
& 9 & 315.2 & 102 & 0.907 & 81.5 \\
& 13 & 651.0 & 83 & 0.911 & 91.1 \\
& 17 & 780.5 & 82 & 0.925 & 92.5 \\
& 21 & 1040.0 & 79 & 0.944 & 94.4 \\
\hline
\end{tabular}

\section{EFM measurement}

EFM is a technique that can directly and quickly determine the corrosion current values without knowing of the Tafel slopes, and with only a small polarizing signal. These advantages of EFM technique make it an ideal candidate for online corrosion monitoring [56]. The causality factors serve as an internal check on the validity of EFM measurement. The causality factors CF-2 and CF-3 are calculated from the frequency spectrum of the current responses. Figure 9 shows the EFM Intermodulation spectra (current vs. frequency) of SS 304 in $\mathrm{HCl}$ solution containing different concentrations of compound (C2). Similar curves were obtained for compound (C1) (not shown). The corrosion current density $\left(i_{\text {corr }}\right)$, the Tafel slopes $\left(\beta_{\mathrm{c}}\right.$ and $\beta_{\mathrm{a}}$ ) and the causality factors (CF-2 and CF-3) were determined using the larger peaks. These parameters were shown in Table 9. The data of this Table show that, the addition of $\mathbf{C 1}$ and $\mathbf{C 2}$ compounds to the acidic solution decreases $i_{\text {corr }}$, indicating that $\mathbf{C} 1$ and $\mathbf{C 2}$ compounds inhibit the corrosion of SS 304 in $1.0 \mathrm{M} \mathrm{HCl}$ via adsorption. The causality factors obtained under different experimental conditions are approximately equal to the theoretical values (2 and 3) indicating that the measured data are verified and of good quality. The inhibition efficiencies $I E \%_{\mathrm{EFM}}$ increase by increasing the inhibitor concentrations and was calculated as from Eq. (10):

$$
I E \%_{\mathrm{EFM}}=\left[1-\left(i_{\text {corr }} / i_{\text {corr }}^{0}\right)\right] \times 100,
$$


where $i_{\text {corr }}^{0}$ and $i_{\text {corr }}$ are current densities of corrosion without and with inhibitor, respectively. The protection efficiency obtained from this method is in the order: C2 $>$ C1.
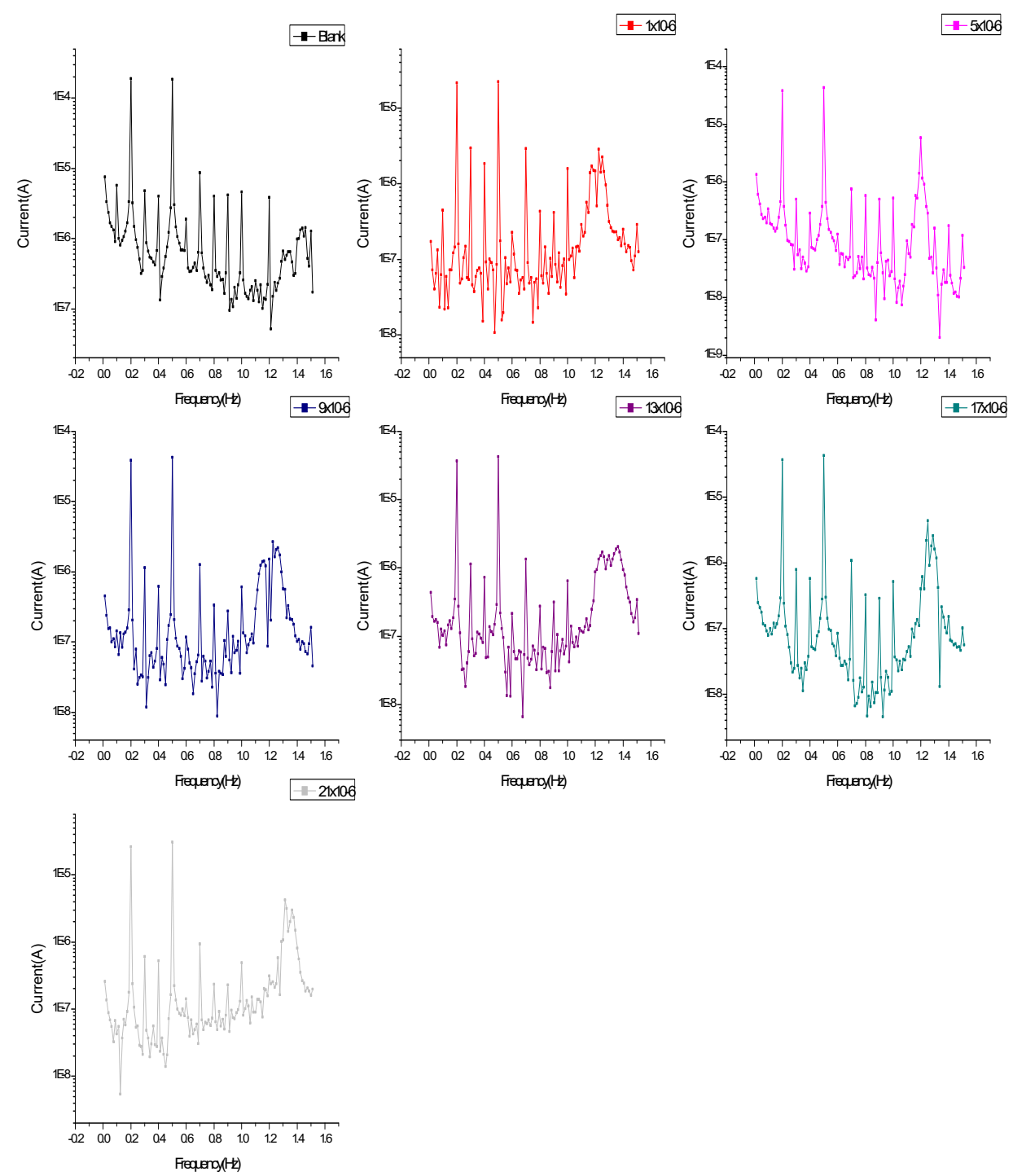

Figure 9. EFM spectra for SS 304 in $1.0 \mathrm{M} \mathrm{HCl}$ in the absence and presence of various concentrations of compound $(\mathbf{C 2})$ at $25^{\circ} \mathrm{C}$.

\section{Mechanism of corrosion protection}

The protection mechanism involves the adsorption of the $\mathbf{C 1}$ and $\mathbf{C 2}$ on SS 304 surface dipped in $\mathrm{HCl}$ solution. Four types of adsorption [57] may take place. These are: 1) Interaction of unshared electron pairs in the molecule with the metal; 2) Interaction of $\pi$ electrons with the metal; 3) Electrostatic attraction between the charged molecules and the charged metal; 4) Combination of all the above. From the observations drawn from the different methods, corrosion inhibition of SS 304 in $1 \mathrm{M} \mathrm{HCl}$ solution by $\mathbf{C 1}$ and $\mathbf{C 2}$ 
compounds as determined from chemical and electrochemical techniques were found to depend on the concentration and the nature of these compound. The order of inhibition efficiency is as follows: $\mathbf{C 2}>\mathbf{C 1}$. This order of decreased inhibition efficiency is due to: $i$ ) compound C2 has higher molecular size, which may cover larger areas from SS 304 surface; $i i)$ it has $3 \mathrm{~N}, \mathrm{O}$ and $\mathrm{S}$ atoms which may act as adsorption centers $(\mathbf{C} 1$ contains $2 \mathrm{~N}$, $\mathrm{O}$ and $\mathrm{S}$ atom), and iii) it contains $\mathrm{Br}$ atom which has dual effect (behaves as acceptor or donator atom), here it acts as donating atom. So compound $\mathbf{C 2}$ is the most efficient inhibitor than compound $\mathbf{C} \mathbf{1}$.

Table 9. Electrochemical parameters obtained from EFM technique for SS 304 in $1.0 \mathrm{M} \mathrm{HCl}$ without and with various concentrations of $\mathbf{C} 1$ and $\mathbf{C} 2$ compounds.

\begin{tabular}{|c|c|c|c|c|c|c|c|c|c|}
\hline Inh. & $\begin{array}{c}{[\text { inh] }} \\
\times 10^{6} \mathrm{M}\end{array}$ & $\underset{\mu \mathrm{Acm}^{-2}}{i_{\text {corr }}}$ & $\underset{m V \text { dec }^{-1}}{\beta_{\mathrm{a}}}$ & $\underset{m V^{\boldsymbol{d e c}_{\mathrm{c}}}}{-1}$ & CF-2 & CF-3 & $\begin{array}{l}\text { C.R. } \\
\text { mpy }\end{array}$ & $\boldsymbol{\theta}$ & $I E \%$ \\
\hline Blank & 0 & 216.8 & 70 & 82 & 1.57 & 2.83 & 99.05 & - & - \\
\hline \multirow{6}{*}{$\mathrm{C1}$} & 1 & 86.94 & 56 & 105 & 1.72 & 2.68 & 11.19 & 0.599 & 59.9 \\
\hline & 5 & 72.05 & 53 & 56 & 1.54 & 2.77 & 15.35 & 0.668 & 66.8 \\
\hline & 9 & 61.82 & 91 & 109 & 1.95 & 3.05 & 28.25 & 0.715 & 71.5 \\
\hline & 13 & 60.69 & 106 & 133 & 1.80 & 2.44 & 32.92 & 0.720 & 72.0 \\
\hline & 17 & 33.59 & 128 & 158 & 1.71 & 2.90 & 39.70 & 0.845 & 84.5 \\
\hline & 21 & 24.50 & 125 & 157 & 1.51 & 2.98 & 27.73 & 0.887 & 88.7 \\
\hline \multirow{6}{*}{$\mathrm{C} 2$} & 1 & 138.1 & 82 & 118 & 1.95 & 2.71 & 32.81 & 0.363 & 36.3 \\
\hline & 5 & 71.8 & 77 & 135 & 1.98 & 2.85 & 13.40 & 0.669 & 66.9 \\
\hline & 9 & 30.38 & 77 & 103 & 1.92 & 2.30 & 63.09 & 0.860 & 86.0 \\
\hline & 13 & 29.33 & 92 & 134 & 2.06 & 2.99 & 11.87 & 0.865 & 86.5 \\
\hline & 17 & 25.97 & 81 & 125 & 2.11 & 3.01 & 13.88 & 0.880 & 88.0 \\
\hline & 21 & 16.48 & 82 & 119 & 1.99 & 2.94 & 7.53 & 0.924 & 92.4 \\
\hline
\end{tabular}

\section{Conclusions}

From the results of the study the following may be concluded. $\mathbf{C} 1$ and $\mathbf{C} 2$ compounds are very good inhibitors for the corrosion of SS 304 in $1.0 \mathrm{M} \mathrm{HCl}$ solution. The protection of these compounds depends mainly on their structures. The variation in protective efficiency depends on the nature and type of the substituents present in $\mathbf{C 1}$ and $\mathbf{C 2}$ molecules. Reasonably good agreement was observed between the values obtained from the weight loss and electrochemical (Polarization, EIS, EFM) measurements. The order of $I E \%$ of $\mathbf{C 1}$ and $\mathbf{C 2}$ compounds is in the following order: $(\mathbf{C 2}>\mathbf{C 1})$. Results obtained from potentiodynamic polarization indicated that the investigated $\mathbf{C 1}$ and $\mathbf{C 2}$ compounds are mixed-type inhibitors. Percentage inhibition efficiency of all investigated compounds was found to depend on temperature and concentration. The thermodynamic parameters 
revealed that the protection of corrosion by $\mathbf{C 1}$ and $\mathbf{C 2}$ compounds is due to the formation of adsorbed film on the metal surface. The adsorption of all investigated compounds onto SS 304 surface follows the Langmuir adsorption isotherm model.

\section{References}

1. M. Abdallah, Mater. Chem. Phys., 2003, 82, 786.

2. C.R. Alentejano and I.V. Aoki, Electrochim. Acta., 2004, 49, 2779.

3. M. Behpour, S.M. Ghoreishi, N. Mohammadi and M.N. Salavati-Niasari, Corros. Sci., $2005, \mathbf{5 3}, 3380$.

4. A. Galal, N.F. Atta and M.H.S. Al-Hassan, Mater. Chem. Phys., 2005, 89, 38.

5. L. Narvaez, E. Cano and D.M. Bastidas, J. Appl. Electrochem., 2005, 35, 499.

6. A.Galal, N.F. Atta and M.H.S. Al-Hassan, Mater. Chem. Phys., 2005, 89, 28.

7. T. Sourisseau, E. Chauveaub and B. Barouxa, Corros. Sci., 2005, 47, 1097.

8. S.A.M. Refaey and A.M. Taha, Int. J. Electrochem. Sci., 2006, 1, 80.

9. A.B. Silva, S.M.L. Agostinho, O.E. Barcia, G.G.O. Cordeiro and E. D'Elia, Corros. Sci, 2006, 48, 3668.

10. D. Gopi, S. Manimozhi, K.M. Govindaraju, P. Manisankar and S. Rajeswari, J. Appl. Electrochem., 2007, 37, 439.

11. A.S. Fouda and H. El-Dafrawy, Int. J. Electrochem. Sci., 2007, 2, 721.

12. A. Yagan, N.O. Pekmez and A. Yildiz, Electrochim. Acta. 2008, 53, 2474.

13. A. Pardo, M.C. Merino, A.E. Coy, F. Viejo, R. Arrabal and E. Matykina, Corros. Sci., 2008, 50, 780 .

14. A.K. Satpati and P.V. Ravindran, Mater. Chem. Phys., 2008, 109, 352.

15. A. Pardo, M.C. Merino, A.E. Coy, F. Viejo, R. Arrabal and E. Matykina, Corros. Sci, 2008, 50, 1796.

16. M. Finsgar, S. Fassbender, F. Nicolini and I. Milosev, Corros. Sci., 2009, 51, 525.

17. M. Behpour, S.M. Ghoreishi, N. Soltani and M.Salavati-Niasari, Corros. Sci., 2009, 51, 1073.

18. M. Finsgar, S. Fassbender, S. Hirth and I. Milosev, Mater. Chem. Phys., 2009, 116, 198.

19. A.S. Fouda and A.S. Ellithy, Corros. Sci., 2009, 51, 868.

20. A.S. Fouda, M. Abdallahb, S.M. Al-Ashreya and A.A. Abdel-Fattahb, Desalination, 2010, 250, 538.

21. F. Nada, A.M. Atta and M.H. Hamdi, Int. J. Hydrogen Energy, 2011, 36, 6462.

22. M.B. Gonzalez and S.B. Saidman, Corros. Sci., 2011, 53, 276.

23. A. Davoodi, M. Pakshir, M. Babaiee and G.R. Ebrahimi, Corros. Sci., 2011, 53, 399.

24. A. Oncul, K. Coban, E. Sezer and B.F. Senkal, Progr. Org. Coat., 2011, 71, 167.

25. N. Caliskan and E. Akbas, Mater. Chem. Phys., 2011, 126, 983.

26. A.S. Fouda, A.M. El-desoky and H.M. Hassan, Int. J. Electrochem. Sci., 2013, 8, 5866.

27. N. Soltani, N. Tavakkoli, M. Khayatkashani, M. RezaJalali and A. Mosavizade, Corros. Sci., 2012, 62, 122. 
28. Yu.I. Kuznetsov, Int. J. Corros. Scale Inhib., 2012, 1, no. 1, 3. doi: $10.17675 / 2305-$ 6894-2012-1-1-003-015

29. V.V. Ekilik, E.A. Korsakova and A.G. Berezhnaya, Int. J. Corros. Scale Inhib., 2013, 2, no. 1, 30. doi: $10.17675 / 2305-6894-2013-2-1-030-038$

30. R.V. Kashkovskiy and Yu.I. Kuznetsov, Int. J. Corros. Scale Inhib., 2012, 1, no. 2, 117. doi: $10.17675 / 2305-6894-2012-1-2-117-129$

31. A.A. Fadda, E. Abdel-Latif and R.E. El-Mekawy, Eur. J. Med. Chem., 2009, 44, 1250.

32. Glixx Laboratories, CAS: 16081-93-9, Cat No: GLXC03806.z.

33. G.N. Mu, T.P. Zhao, M. Liu and T. Gu, Corrosion, 1996, 52, 853.

34. K.F. Khaled, Mater. Chem. Phys., 2008, 112, 290.

35. K.F. Khaled, J. Appl. Electrochem., 2009, 39, 429.

36. R.W. Bosch, J. Hubrecht, W.F. Bogaerts and B.C. Syrett, Corrosion, 2001, 57, 60.

37. S.S. Abdel-Rehim, K.F. Khaled and N.S. Abd-Elshafi, Electrochim. Acta, 2006, 51, 3269 .

38. A. Yurt, G. Bereket, A. Kivrak, A. Balaban and B. Erk, J. Appl. Electrochem., 2005, 35, 1025.

39. F. Bentiss, M. Traisnel and M. Lagrenee, Corros Sci., 2000, 42, 127.

40. W. Durnie, R.D. Marco, A. Jefferson and B. Kinsella, J. Electrochem. Soc., 1999, 146, 1751.

41. G.Banerjee and S.N. Malhotra, Corrosion, 1992, 48, 10.

42. F. Bentiss, M. Lebrini and M. Lagrenee, Corros. Sci., 2005, 47, 2915.

43. J. Marsh, Advanced Organic Chemistry, 3rd edn. (Wieley Eastern, New Delhi), 1988.

44. D.C. Silverman and J.E. Carrico, Corrosion, 1988, 44, 280.

45. W.J. Lorenz and F. Mansfeld, Corros. Sci., 1981, 21, 647.

46. D.D. Macdonald and M.C. Mckubre, Impedance measurements in Electrochemical systems, in Modern Aspects of Electrochemistry, J.O'M.Bockris, B.E.Conway, R.E.White, Eds., Vol. 14, Plenum Press, New York, 1982, 61.

47. M. El Achouri, S. Kertit, H.M. Gouttaya, B. Nciri, Y. Bensouda, L. Perez, M.R. Infante and K.Elkacemi, Prog. Org. Coat., 2001, 43, 267.

48. J.R. Macdonald and W.B.Johanson, in: Theory in Impedance Spectroscopy, J.R. Macdonald (Ed.), John Wiley\&Sons, New York, 1987.

49. S.F. Mertens, C. Xhoffer, B.C. Decooman and E. Temmerman, Corrosion, 1997, 53, 381.

50. G. Trabanelli, C. Montecelli, V. Grassi and A. Frignani, J. Cem. Concr. Res., 2005, 35, 1804.

51. A.J. Trowsdate, B. Noble, S.J. Haris, I.S.R. Gibbins, G.E. Thomson and G.C. Wood, Corros. Sci., 1996, 38, 177.

52. F.M. Reis, H.G. De Melo and I. Costa, Electrochim. Acta, 2006, 51, 17.

53. M. Lagrenee, B. Mernari, M. Bouanis, M. Traisnel and F. Bentiss, Corros. Sci., 2002, 44, 573.

54. E. McCafferty, N. Hackerman, J. Electrochem. Soc., 1972, 119, 146. 
55. H. Ma, S. Chen, L. Niu, S. Zhao, S. Li and D. Li, J. Appl. Electrochem., 2002, 32, 65. 56. E. Kus and F. Mansfeld, Corros. Sci., 2006, 48, 965.

57. G.A. Caigman, S.K. Metcalf and E.M. Holt, J. Chem. Cryst., 2000, 30, 415. 